\title{
Healthcare Providers and Outpatients Relationship: A Study of Three Selected Public Hospitals in Sokoto Metropolis
}

\author{
Bello Almu ${ }^{1}$, Dankani Ibrahim Mustapha ${ }^{2}$ \\ ${ }^{I}$ Medical Social Services Department, Usmanu Danfodiyo University Teaching Hospital, Sokoto, Nigeria \\ ${ }^{2}$ Department of Geography, Usmanu Danfodiyo University, Sokoto, Nigeria
}

\begin{abstract}
This paper examines healthcare providers and outpatients relationships in three selected public hospitals in Sokoto metropolis. It is the contention of this paper that good interpersonal relationship is the key to the health and wellbeing of patients. In fact the professional ethics of healthcare givers revolves around promotion of human dignity; observation of professional ethics and respect; orientation for quality services; patients centered management; and possession of good interpersonal relationship. Data for the study was collected via administration of structured questionnaire at three public health facilities ranging from primary health care facility (Kofar Rini PHC), secondary health facility (Specialist Hospitals) and a tertiary health facility (Usmanu Danfodiyo University Teaching Hospital Sokoto). A total of 450 respondents were selected purposively for the study. Major findings of study reveals that there seems to be a cordial relationship between healthcare givers and their patients and the management of the hospital provided an effective and efficient ways a lodging complaints or displeasure with service delivery. The study concludes by recommending ways to reduce long queues and waiting time by employment of more staffs and also the hospital management needs to be organizing regular training for staff on ethics, rules and regulations.
\end{abstract}

Keywords: Healthcare Providers, Outpatients, Relationship, Hospitals, Sokoto.

\section{INTRODUCTION}

$\mathrm{T}$ The Orthodox Healthcare Service System or Western Cosmopolitan Healthcare Service system is a very significant institution across the globe, and equally, is a recognized health care delivery system in Nigeria (Nabuyye et al., 2011). This system is so organized that every functioning part of the system has its own peculiar role to play. These parts include the team of officers with designated duties to carry out healthcare service delivery based on their respective professions. The officers range from physicians, laboratory scientists, nurses, medical records personnel, administrators, social workers and radiographers among others. The practice involved activities which if not professionally handled could lead to litigations or criminal charges (Adejumo and Oluseyi, 2020).

Patients are expected to derive some satisfactory benefits from this kind of cosmopolitan setting. Patients trust to healthcare providers on the other hand was also expected primarily
(Berger et al., 2020) and necessarily. This is noticed as being one of the key qualities to assess the performance of facilities and a yardstick to prove the potentiality of the system, whether it has worked well or otherwise. The pattern for the satisfactions covered all areas of health service delivery (Adejumo and Oluseyi, 2020).

According to Umar et al., (2011), the complete satisfaction of patients lies in the efficiency and the potentiality of a relevant organization to deliver effective services. Lack of favorable circumstances, enabling environment or lack of satisfaction (Akunne et al., 2019); lack of cordial relationship lead to loss of trust and satisfaction (Berger et al., 2020). On the same note, resulted in substantive number of patients rejecting as well as showing lack of interest in patronizing a particular healthcare center. In other word, "the arrogant DoctorPatients relation in governmentt hospital signifies why the utilization is low" (Asakitikpi, 2019).

Previous research works (Whte and Goodacre, 2015, Bamidele et al., 2011, Zineldin, 2011, Anastasia et al., 2014 and Mosinguzi 2015, Oladapo et al., 2008, Bergenner et al., 2006, and Bernhart et, al. 1999 among others) have shown that, patients have suffered tremendously from some existing kind of treatment and relationship especially on how they are managed; how they spent much money; and how they expended much time awaiting services. In addition, long waiting hours even in receiving medication, lack of trust, poor infrastructures, in adequate funding and many several reasons which contributed to poor satisfaction with health services experienced by patients in Nigeria. Asakitikpi et al., (2019) further cited problems of access to patronage and the healthcare ratio to patients were also some of the challenges depriving patients to patronize hospital. These are great factors determine the perception of patients towards any given facility (Wafula, 2016).

It is unfortunate, healthcare providers breach fundamental human right, engaged in negligence of duty and fiduciary relationship with patients(Akunne et al., 2019); outpatients also were treated wrongly and below expectations, which might make them look for other better alternative or lose confidence on their handling in the healthcare sectors. In the same vein, large number of patients suffers from exhaustive queues, discriminatory attitudes and practices, long waiting 
time (Umar, 2011) and verbal abuse by healthcare providers ( Neill and obarein, 2014). Physicians considered patients in pragmatic manner (Berger et al., 2020). In some cases, negligence for duty and fiduciary led to injury to the patient or patient's death (Akunne et al., 2019). No doubt, the social interaction between physicians and patients' recorded low (Berger et al., 2020). These unsatisfactory practices of healthcare providers are regarded as maltreatment of patients (Bernhart et al., 1999). In the same manner, patients face harmful experiences which include: neglect and mistreatment, unkind and unfair treatment, treating patients based on personal attributes (such as class, ethnicity and gender). It is the contention of this study that patients in public hospitals are more prone to poor treatment and neglect due to the fact that majority of the outpatients are the poor and the middle income groups that cannot afford the services of private hospitals and clinics. These resulted many patients that are well to do to seek medical intervention abroad, especially cases related to neurology, cancer, cardiology and other forms of surgeries among others (Akunne et al., 2019). Most of the favorable relationship could be attributed to the ability of physicians to solve the patient's problem (Berger et al., 2020). Furthermore, healthcare providers were guided by ethics and principles which have failed to match with those ethics (Asakitikpi, 2019).

The dearth of study of this nature in Sokoto state underscore the need for a study to examine the relationship that exist between Heath care providers and outpatients in public hospitals in Sokoto metropolis. The study seeks to bridge this gap in Knowledge by describing the nature of the existing relationship between outpatients and healthcare providers as the objective of the study.

\section{THEORETICAL FRAMEWORK: (PATIENTS CENTERED CARE)}

This research employed Patient Centered Care (PCC) approach. The concept of Patient Centered Care was coined by Abdellah and Wiedenbanet in 1960 (Nurse Theorists). Patient Centered Care (PCC) is defined as the standard practice that demonstrates respect for a patient as a person seeking medical and healthcare assistance (Shaller (2007) cited in Macdonald (2017); Binnie and Chen (1999); Redman (2004)).

The patient centered care is a practice of caring for patients in a meaningful and valuable way. This consists of careful listening, discussing, informing and involvement of a patient on his management, care and control for result-oriented services transmission or delivery.

The basic assumptions of the theory in accordance with Macdonald (2017) and Pelzang (2010) are as follows:

- Patients are the focus centre of the healthcare system delivery.

- Patients are whole persons who have physical, psychological, and social needs and are qualified to identify their needs for consideration and evaluation.
- Patients are assumed to make decisions based on their needs, conditions and situations needing immediate expert intervention.

- Patients are considered as persons rather than clusters of diseases.

- Patients should be involved in the management of their cases.

The fundamental features of PCC based on the assumptions is the individualization of patients, involvement of patients in their own decision making and shared decisions (Robinson et al.,2008).

This model has emerged due to limitations in conventional biomedical model, in which an illness is taken as an indicator to the existence of diseases (Mead and Brower, 2000).

Picker Institute and Harvard Medical Schools identified eight (8) principles of patient centered care; as follows:

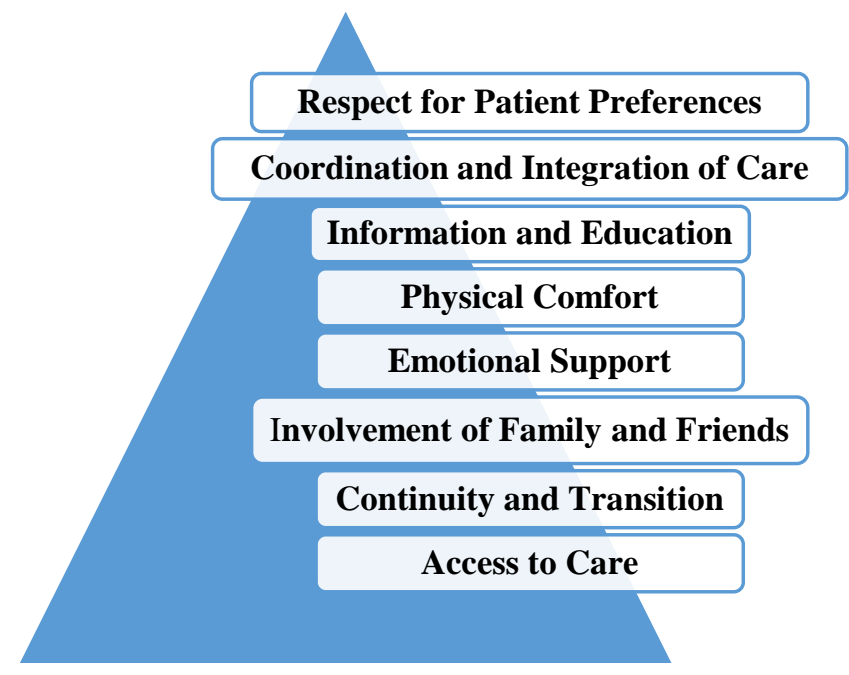

Gerteis, 1993

Figure 1: Picker Eight Principles of Patient Centered Care

- Respect for a patient's preference: This has to do with involving a patient in decision making; treating a patient with respect; dignity; and showing sensitivity to cultural preferences.

- Coordination and integration: This has to do with coordination of clinical care; support services; and front line of patients' care.

- Information and education: This has to do with information on clinical status; progress; procedures; and information regarding a medical facility.

- Physical comfort: This has to do with the areas of pain management; hospital environment tidiness; and assistance of a patient in his daily living in a medical facility.

- Emotional support: This has to do with a patient's anxiety especially in areas of his or her physical status; prognosis; and cost of financial implication to the patient's. 
- Involvement of family and friends: This has to do with the involvement of his or her family and friends in decision making and support services rendered to a patient.

- Continuity and transition: this has to do with coordinating of ongoing plans and treatment in clear instruction for effective transition while staying in a medical facility.

- Access to care: This has to do with flexible appointment and access to specialization and services whenever needed.

The other processes entailed in a patient Centered Care include working hand in hand with patients belief and values, provision of physical, social and psychological needs; sharing of decisions and results. Furthermore, a patients centered care principle has to do with the patient's values and beliefs, in decisions making. Thus, healthcare Professionals' attributes should be in line with the principles that include being professionally competent; possessing good interpersonal and communication skills and having full commitments to medical and health services. In the same manner, medical and healthcare organizations should possess certain attributes which include: time, health workers role, effective staff relations and shared decision making; while a patients attributes consists of his perception of care, his/her participation and cooperation (Pelzang, 2010) and positive responses to treatment.

Based on the aforementioned, a successful patient centered care outcome is that which a outpatient is satisfied with at the level of services he receives. It can be through his/her involvement in decision making regarding his or her treatment, and the feeling of being well attended regarding health condition (Macdonald, 2017)

The application of a patient centered theory is one of the best ways to handle outpatients in these three selected public study hospitals. This is so because, each healthcare professional within a hospital should have prescribed roles and ethics, which will have positive impact to a patient, a hospital is supposed to be designed in a standard form to provide quality healthcare services. Thus, most of outpatients' dissatisfaction could emanate from breach of these ethics (Asakitikpi, 2019). The theory has shortcomings despite its relevance, as no theory is perfect. The theory has put much emphasis on patients care and respect, thereby neglecting the individual nature of behaviour. Some patients can be stubborn, selfish and hence needs to be control. Respect for patients would not be always possible and yield positive result where such patients express certain kinds of ill-mannered behaviour.

\section{METHODOLOGY}

This section focuses on the methods adopted in the course of the study ranging from the research design, sampling techniques and mode of data analysis and presentation.

\section{Research Design}

Quantitative method was employed in the study. The study is also cross-sectional in three selected hospitals Kofar Rini (Primary Healthcare Centre), Specialist Hospital Sokoto (Secondary Healthcare Centre) and Usmanu Danfodiyo University Teaching Hospital Sokoto (Tertiary Healthcare Centre). The method used in collecting of the data was through administration of semi structured questionnaire.

\section{Location of the Study}

The study was carried out in Sokoto Metropolis and three (3) selected public facilities were used. One (1) is primary health institution, one (1) is secondary health institution and one (1) is tertiary healthcare institution. (Kofar Rini generalist hospital, located at Sokoto North Local 2Q Government area; Sokoto Specialist Hospital, located opposite Nagarta College in Sokoto South Local Government Area; and Usmanu Danfodiyo University Teaching Hospital, Sokoto which is located at Garba Nadama road in Wamakko Local Government Area.

\section{Study Population}

The study populations were the willing outpatients during the period for data collections (2018) in the three (3) selected study areas.

\section{Sampling Size and Procedure}

Purposive sampling was used in selection of respondents. Ratio formula was adopted based on the level/capacity of study facilities Using purposive sampling, it is difficult to predict the sample sizes; notwithstanding, the study worked with 450 sample size \{ primary= ratio 1: $6(75: 450)$; secondary $=2: 6(150: 450)$; and tertiary $=$ ratio $3: 6(150: 225)\}$ and the data was collected within three (3) months period.

\section{Instrument and Method of Data Collection}

The instrument used for data collection was Semi structured questionnaire, designed in two sections. The questionnaire was self-administered. Section A contained the demographic characteristics of respondents; while section $\mathrm{B}$ was on the relationship between healthcare providers and outpatients. The natures of questions were open and closed ended.

\section{Method of Data Analysis}

The use of frequency, simple percentage, bar chart and the cross tabulation was adopted in the study. The data was analyzed with the aid of Statistical Package for Social Sciences (SPSS) software.

\section{Ethical Considerations}

Participation to the study was voluntarily and the researcher has explained to respondents. In line with ethics of conducting research, the researcher sought and was granted the ethical approval from the State Ministry of Health, Sokoto State. 


\section{RESULTS AND DISCUSSIONS}

Four hundred and fifty (450) copies of questionnaire were administered but the study worked with three hundred and ninety nine (399) valid questionnaires only.

\section{Socio-economic Characteristic of the Respondents}

This section examines the socio-economic characteristics of the respondents.

\begin{tabular}{|c|c|c|}
\hline Demographic variable & Frequency & Percentage \\
\hline \multicolumn{3}{|c|}{ Sex } \\
\hline 1. Male & 203 & 50.9 \\
\hline 2. Female & 196 & 49.1 \\
\hline \multicolumn{3}{|c|}{ Age } \\
\hline 1. $26-33$ & 137 & 34.3 \\
\hline 2. $34-41$ & 95 & 23.8 \\
\hline 3. $42-49$ & 75 & 18.8 \\
\hline 4. $18-25$ & 71 & 17.8 \\
\hline 5. 50-Above & 21 & 5.3 \\
\hline \multicolumn{3}{|c|}{ Marital status } \\
\hline 1. Married & 246 & 61.7 \\
\hline 2. Single & 88 & 22.1 \\
\hline 3. $\quad$ Separated & 25 & 6.3 \\
\hline 4. Divorced & 24 & 6.0 \\
\hline 5. $\quad$ Widowed & 16 & 4.0 \\
\hline \multicolumn{3}{|c|}{ Religion } \\
\hline 1. Islam & 339 & 85.0 \\
\hline 2. Christianity & 60 & 15.0 \\
\hline \multicolumn{3}{|c|}{ Ethnic background } \\
\hline 1. Hausa & 241 & 60.4 \\
\hline 2. $\quad$ Fulani & 63 & 15.8 \\
\hline 3. Igbo & 40 & 10.0 \\
\hline 4. Yoruba & 40 & 10.0 \\
\hline 5. Others & 15 & 3.8 \\
\hline \multicolumn{3}{|c|}{ Educational qualification } \\
\hline 1. Tertiary education & 180 & 45.1 \\
\hline 2. Secondary education & 102 & 25.6 \\
\hline Qur'an education only & 78 & 19.5 \\
\hline Primary education only & 23 & 5.8 \\
\hline 5. $\quad$ No formal education & 16 & 4.0 \\
\hline \multicolumn{3}{|c|}{ Occupation } \\
\hline 1. Civil service & 127 & 31.8 \\
\hline 2. $\quad$ Trading & 99 & 24.8 \\
\hline 3. Unemployed & 95 & 23.8 \\
\hline 4. $\quad$ Farming & 49 & 12.3 \\
\hline 5. Others & 29 & 7.3 \\
\hline
\end{tabular}

Table 1: Socio-economic Characteristics of the Respondents ( $N=399)$

Investigation into the sex of respondents reveals that male constitutes the majority with $50.9 \%$. This finding seems surprising considering the fact that women are most often than not those taking family members to hospital during an ailment. The fact that the society is patriarchal and male as heads of household are saddled with the responsibility of provision of basic needs of the family made males to be more engaged in looking for means of livelihood and thus have little time to take family members to hospital unless in cases of emergency. Age distribution of the respondents shows that those between the age brackets of 26-33 were the majority with $34.3 \%$ and they are followed by $23.8 \%$ who falls within the ages of 34-41. This finding indicates that most of the respondents are matured enough to gauge and assess the nature treatment meted to them by health care givers. In terms of marital status, married couples constitutes the majority with $61.7 \%$, single constitutes $22.1 \%$ while widowed accounted for $4 \%$. The religious belief of respondents shows that Muslims are the majority with $85 \%$. The location of the study area is one of the major Muslim dominate areas of Nigeria. In fact the population is more than $90 \%$ Muslim. Furthermore, the ethnic composition of the respondents shows that Hausa constitutes the majority with $60.4 \%$ and they are followed by Fulani with $15.8 \%$. Igbo and Yoruba accounted for $10 \%$ each. Educationally, majority of the respondents $(45.1 \%)$ attended tertiary institution, $25.6 \%$ are secondary school certificate holders while $19.5 \%$ have Quran education as their form of educational attainment. There seems to be a kind of synergy between people's level of education and their choice for medical healthcare. Educated people are ever willing to attend healthcare facility than the illiterates. Similarly, the presence of so many tertiary institutions within the metropolis could also be a contributing factor for the dominance of those with tertiary education among the sampled respondents. It can also be understood that a lot of educated people, civil servants etc have registered with National Health Insurance Scheme (NHIS) and majority adopted hospitals like UDUTH as a choice center for treatment. Occupationally, Civil servants constitute the majority with $31.8 \%$. Traders and unemployed accounted for $24.8 \%$ and $23.8 \%$ respectively. The dominance of civil servants and traders could be attributed to the urban nature of the study area where majority of the population engages in either secondary or tertiary economic activity. Traders and civil servants are capable of affording hospital bills and are willing to spend to get the best service delivery. The occupational distribution also shows that $23.8 \%$ of the respondents are unemployed. One critical challenge confronting most urban centers in Nigeria is there are more manpower than the city can absorb thereby resulting in huge unemployment particularly among the youth.

\section{Relationship between Healthcare Providers and Outpatients}

This section consists of eight set of questions presented in Table 2 and Table 3, targeted to assessing the relationship between the healthcare providers and the outpatients. 
Table 2: Relationship between Healthcare Providers and Outpatients 1 $(\mathrm{N}=399)$

\begin{tabular}{|c|c|c|c|}
\hline Questions & Response & $\begin{array}{c}\text { Freq } \\
\text { uenc } \\
y\end{array}$ & $\begin{array}{l}\text { Perce } \\
\text { ntage }\end{array}$ \\
\hline $\begin{array}{l}\text { What do you } \\
\text { enjoy from } \\
\text { healthcare } \\
\text { provider in the } \\
\text { hospital } \\
\text { attended? }\end{array}$ & $\begin{array}{l}\text { Booking for me before I arrive } \\
\text { hospital } \\
\text { Link me to other places to access } \\
\text { services } \\
\text { Stand for me during a particular } \\
\text { services } \\
4 . \quad \text { None of the above } \\
5 . \quad \text { Others (specify) }\end{array}$ & $\begin{array}{c}121 \\
88 \\
68 \\
118 \\
4\end{array}$ & $\begin{array}{c}30.3 \\
22.1 \\
17.0 \\
29.6 \\
1.0\end{array}$ \\
\hline $\begin{array}{l}\text { Do you have } \\
\text { any form of } \\
\text { relationship } \\
\text { with } \\
\text { healthcare } \\
\text { providers from } \\
\text { the hospital } \\
\text { attended }\end{array}$ & $\begin{array}{l}\text { Yes, because we called each other } \\
\text { occasionally } \\
\text { Yes, because I once visited him } \\
\text { Yes because he considers me as } \\
\text { relative } \\
\text { No, because none of the above } \\
\text { 5. Others (specify) }\end{array}$ & $\begin{array}{l}110 \\
90 \\
85 \\
99 \\
15\end{array}$ & $\begin{array}{c}27.6 \\
22.6 \\
21.3 \\
24.8 \\
3.8\end{array}$ \\
\hline $\begin{array}{l}\text { Do you } \\
\text { forward any } \\
\text { complaint to } \\
\text { the } \\
\text { Management } \\
\text { team? }\end{array}$ & $\begin{array}{l}\text { Maintenance of confidentiality } \\
\text { Complain of hygienic environment } \\
\text { Complain of long waiting time } \\
\text { 4. No room for complaint } \\
\text { 5. Others (specify) }\end{array}$ & $\begin{array}{c}117 \\
96 \\
126 \\
53 \\
7\end{array}$ & $\begin{array}{c}29.3 \\
24.1 \\
31.6 \\
13.3 \\
1.8\end{array}$ \\
\hline $\begin{array}{l}\text { Are you } \\
\text { comfortable } \\
\text { with the } \\
\text { hospital you } \\
\text { attended? }\end{array}$ & $\begin{array}{l}\text { Yes, I can disclose my secret to } \\
\text { Doctors } \\
\text { Yes, I can channel my grievances } \\
\text { to them } \\
\text { No, I cannot disclose my secrets to } \\
\text { them } \\
\text { 4. No, I cannot channel my } \\
\text { grievances } \\
\text { 5. Others (specify) }\end{array}$ & $\begin{array}{c}176 \\
114 \\
71 \\
32 \\
6\end{array}$ & $\begin{array}{c}44.1 \\
28.6 \\
17.8 \\
8.0 \\
1.5\end{array}$ \\
\hline
\end{tabular}

Information in Table 2 revolves around relationship between Healthcare providers and the outpatients. The Table comprises of four questions meant to elicit responses from the respondents on the nature of relationship that exist between them and healthcare givers. Investigation into what the respondent enjoy from the health givers shows that $30.3 \%$ claimed booking for appointment is made for them before they arrived the hospital. $22.1 \%$ claimed the healthcare givers link them up with other places to access services while $17 \%$ narrated that the healthcare givers do stand for them during a particular services. A total of $29.6 \%$ of the respondents stated that they did not enjoy any services from the healthcare personnel. Going by this finding, it is clear that healthcare givers gives assistance in one way or the other to the patients. This surely increases the confidence of the patients of receiving good care whenever they attend health facilities for medical care.

With respect to whether the respondents have any form of relationship with healthcare providers, information in Table 2 indicates that majority of the respondents $(27.6 \%)$ responded with yes because they maintain relationship by calling each other. $22.6 \%$ also responded with yes and the reason adduced was that the patient visits the healthcare provider. Furthermore, $2.13 \%$ of those who responded with yes stated that healthcare provider considered them just like relatives.
On the other hand $24.8 \%$ of the respondents responded with no signifying that they did not consider healthcare providers as relations. Following up patients and monitoring their wellbeing is very important in healthcare delivery. It goes a long way in reminding the patients of their responsibilities and obligations towards their health and also ensures easy access to healthcare givers in times of emergencies because the healthcare giver can easily be accessed. The era of mobile phone and chats applications have made communication and interpersonal relationship easy and seamless.

On whether respondents forward their complaints to the management, information in Table shows reveals that $31.6 \%$ of the respondents claimed to have complained of long waiting time before accessing healthcare, $24.1 \%$ stated that they have complained about the hygienic nature of the environment of the facility they attended, $29.3 \%$ of the respondents claimed that they made complain on maintenance of confidentiality while $13.3 \%$ stressed that there is no room for one to make or lay complaints. One of the major challenges confronting patients' at most public hospital is the issue of delay, long queues and waiting period. The huge amount of patients that troops to public hospitals are enormous. This situation is also compounded by fewer number of healthcare providers compared to the patients. This resulted in long queues and waiting time. The fact that only $13.3 \%$ of the respondents stressed that there is no room for complaint indicates that the hospital management have listening ears and are willing to make amends in order to improve the quality of services rendered to patients.

With respect to the question on whether respondents are comfortable with the healthcare facility they attended, Table 2 indicated that $44.1 \%$ of the respondents indicated yes and can disclose their secrets to the health personnel. Similarly, $28.6 \%$ of the respondents responded with yes because they can channel their grievances to the healthcare givers. On the other hand $17.8 \%$ and $8.0 \%$ of the responded with no because they cannot disclose their secrets to health personnel and they cannot channel their grievances to the healthcare givers respectively. Feeling at ease with healthcare givers is one of the critical way of understanding and unearthing the genesis of ailment of a patients. This positive relationship is vital particularly to ailments that people are embarrassed to disclose to anybody.

Table 3: Relationship between Healthcare Providers and Outpatients 2 $(\mathrm{N}=399)$

\begin{tabular}{|c|c|c|c|c|}
\hline Question & \multicolumn{2}{|c|}{ Response } & $\begin{array}{c}\text { Freq } \\
\text { uenc } \\
\text { y }\end{array}$ & $\begin{array}{c}\text { Perce } \\
\text { ntage }\end{array}$ \\
\hline Maximum & 1. Less than 10 minute & 153 & 38.3 \\
time ever & 2. Less than 20 minute & 97 & 24.3 \\
spend with & 3. Less than 30 minute & 79 & 19.8 \\
Physicians & 4. Less than 40 minute & 43 & 10.8 \\
& 5. 40 minute and above & 27 & 6.8 \\
\hline Recognizing & Yes, he uses to assist him on my & 161 & 40.4 \\
any of & \multicolumn{2}{|c|}{ case } & 121 & 30.3 \\
outpatient's & Yes, he used to asked when he & 72 & 18.0 \\
family & \multicolumn{2}{|c|}{ did not come } & 42 & 10.5 \\
member or & No, they have never asked for & 3 & .8 \\
\hline
\end{tabular}




\begin{tabular}{|c|c|c|c|}
\hline friend & $\begin{array}{l}\text { them } \\
\text { No, they don't know any of them } \\
5 \text {. Others (specify) }\end{array}$ & & \\
\hline $\begin{array}{l}\text { One gesture } \\
\text { ever benefited } \\
\text { from }\end{array}$ & $\begin{array}{l}\text { Used to call when I missed } \\
\text { appointment } \\
\text { Calculation for me my next } \\
\text { appointment } \\
\text { Assisted me financially when } \\
\text { exhausted } \\
\text { 4. None of the above } \\
\text { 5. Others (specify) }\end{array}$ & $\begin{array}{c}120 \\
134 \\
55 \\
88 \\
2\end{array}$ & $\begin{array}{c}30.1 \\
33.6 \\
13.8 \\
22.1 \\
.5\end{array}$ \\
\hline $\begin{array}{l}\text { Access to } \\
\text { healthcare is a } \\
\text { right. }\end{array}$ & $\begin{array}{l}\text { Yes, I was told by my managing } \\
\text { team } \\
\text { Yes, it was proved to me by my } \\
\text { Doctors } \\
\text { No, it proved to me otherwise } \\
\text { No, it depends on one's personal } \\
\text { attributes } \\
5 \text {. Others (specify) }\end{array}$ & $\begin{array}{c}197 \\
114 \\
31 \\
56 \\
1\end{array}$ & $\begin{array}{c}49.4 \\
28.6 \\
7.8 \\
14.0 \\
.3\end{array}$ \\
\hline
\end{tabular}

Table 3 also focuses on the relationship between healthcare givers and the respondents and it comprises of four questions.

Investigation into the maximum time ever spent with physicians reveals that, Majority of the respondents (38.3\%) claimed to have spent less than 10 minutes with the physician. Less than 20 minutes and less than 30 minutes accounted for $24.3 \%$ and $19.8 \%$ of the responses respectively. Only $6.8 \%$ of the respondents claimed to have spent 40 minutes and above with physicians. As a mentioned earlier, large number of patients and fewer numbers of healthcare givers compelled most healthcare givers to quickly attend to patients in order to save time for others. It is obvious that less than 10 minutes is grossly inadequate to attend to healthcare seeker and going by the finding of this study over $80 \%$ of the patients claimed they spent less than 30 minutes during consultation. By implication, the healthcare giver might do not dedicate enough time to attend to and listen to the patient. This often results in wrong diagnosis and worsening of the situation of the patients.

On whether the physicians recognize any of the outpatients family member or friends, information in Table 3 indicated that $40.4 \%$ of the respondents responded with yes and the reasons adduced was that the physicians used to assist family members whenever you attended the facility. 30.3\% responded with yes because the physicians do ask of patient's relatives whenever they did not come together. On the other hand, $18.0 \%$ and $10.5 \%$ of the respondents responded with no because the physician never ask of their relatives and physicians do not know any of their relatives respectively.

Respondents were asked to name one gesture ever benefitted from healthcare providers of the facility they attended. In response to the question, $49.4 \%$ of respondents stated that the physician do call them when they miss appointment, $33.6 \%$ stated that the physician often calculate for them the next time of appointment. $13.8 \%$ stated that they were assisted financially by the healthcare providers particularly when they exhaust their money. On the other hand $22.1 \%$ of the respondents stated that they have never benefitted from any gesture from the healthcare service providers.
On whether the respondents believe access to health care is a right, $49.4 \%$ responded with yes because they were told by managing team of the facility they attended. Another $28.6 \%$ also responded with yes because it was proved them by the management team while $7.8 \%$ and $14.0 \%$ responded with no because it was never proved to them at the facility they attended and no because access depend on one's personal attributes respectively.

This finding of this study proves a good working relationship between healthcare givers and patients/relatives of patients and it concurs with Pascoe (1983), Harsenet et al (2008) and Morcinowic et al (2009). All of whom in their major argument mentioned, satisfaction of outpatients has always been influenced by interpersonal relationships.

\section{CONCLUSION AND RECOMMENDATIONS}

Healthcare providers are duty bound to ensure satisfaction of their patients via provision of best medical care possible. In fact the importance of good services has been enshrined in the ethics and principles of handling patients which includes promotion of human dignity, observation of professional ethics and respect, orientation for quality services, patients centered management and possession of good interpersonal relationship (WHO, 2005). Based on the above this study has established that there is good relationship between patients and healthcare providers in the 3 hospitals understudy but despite the cordiality in relationship, the study discovered areas that might need improvement in order to enhance quality service delivery.

The following recommendations were therefore put forward:

i. Overcrowding of patients and understaffing need to be address; this would help in settling the genesis of booking before arrival to the facility and complaints for long waiting time.

ii. Entertainment gadgets like television and toys need to be provided so as to reduce the boring of long waiting time.

iii. The hospital management needs to have regular training for Staff on ethics, rules and regulations. This might help healthcare providers to maintain good interpersonal relationships with all patients and at the same time, prevention of favoring one patient against others. The practice of patients centered care approach is also recommended. This would assist with basic knowledge on how to establish good interpersonal relationships with outpatients.

iv. There is need for the managements of these public hospitals to sensitize healthcare providers on the expected outcome in applying well inter personal relationship with patients toward their recovery from their ailment.

\section{REFERENCES}

[1] Adejumo, O. and Oluseyi A. (2020) Legal Perspective on Liability for Medical Negligence and Malpractice in 
Nigeria. Pan African Medical Journal (issn: 1937-8688) Volume $35 \quad(44)$ at http://www.panafrican-medjournal.com/content/article/35/44/full accessed on 3/3/21

[2] Akunne, M. Okuntu, M. Ekkwwunife (2019) Satisfaction of Nigerian Ptients with Health Services: A Protocol for a Systematic Review. BMC systematic Reviews 8 (256)

[3] Asakitikpi, A. (2019) Healthcare Coverage and Affordability in Nigeria: An Alternative Model to Equitable Healthcare Delivery. London, Universal Health Coverage. IntechOpen Publishers. Doi: 10.5.5772/intechopen.85978

[4] Anastasia, P. Pavlos, S. Maliarom, M. Andreas, T. (2014). Assessment of Patient satisfaction of the quality of healthcare provided by outpatient services of an oncology hospital; global journal of health science. Vol 6(5).

[5] Bamidele, P. Hogue, H. Vander (2011). Patients' satisfaction with the quality of care in a Primary healthcare setting in Bostwan; journal of American colleage heath Assr home page

[6] Bergenner M, Nylein U, Lidbunk E. (2006). Improvements in Patient Satisfaction at an outpatient clinic for Patient clinic for breast cancer. International Journal of Healthcare, 7:167-170.

[7] Berger, R. Bulmas, B. Drori, N. Ben-Assuli, O. Herstein, R. (2020)The Patients-Physician Relationship: An account of the Physician's Perspective. Israel Journal of Health Policy Research 9 (33). Bio Med Central ltd ISSN:2045-4015

[8] Bernhart M, Wiadyana I, Wihar H. (1999). Patient satisfaction in developing countries; Social Science medicine, 48:98 9-996

[9] Gerteis, M., Edgman, L., Daley, D. (1993). Through the patient's eyes: understanding and promoting patient centered care- Jossey- bass, San Francisco

[10] Ibrahim, A. (2008). Patients Satisfaction with Health Services at the Outpatient Department of Indira Gandhi Memorial Hospital, Male' Maldives: A Thesis Submitted in Partial Fulfillment of the Requirement for the Degree of Master of Primary Health Care Management, Mahidol University.

[11] Macdonal, M. (2017). What does Patient centered care means and how might/do leaders work with Patients to help shape our health.

[12] Musinguzi, C. (2015). Paitient waiting time and associated factors at the assessment centre, general outpatient department, Mulago hospital, Uganda.
[13] Nabbuye, J. Fredrick, E. Kasangaki, A. Betty I. Tugumisirize, J. Nshimye, E. Mbabali, S. and Peter, D. (2011). Patient satisfaction with services in outpatient's clinics at mulago hospital, Uganda; International journal for quality in Healthcare, volume 23. P516-523

[14] Neill, O. Edim, M. Obarein, B. (2014). Causes of prolong waiting time in Public Health Facilities among Health Care Seekers in Calabar Municipal Council of Cross River State, Nigeria. Research on Humanities and Social Sciences ISSN (paper) 2224-5766.

[15] Oladipo, O. Iyanimna, C. Sule, A. (2008). Quality of Antenatal Services at the Primary Care Level in Southwest Nigeria. African Journal of Reproductive Health. Vol 12 (3). Accessed on 26/12/2017

[16] Pelzang, R. (2010). Time to learn: understanding Patient centered care; British journal of Nursing, Mark Allen Publishing Ltd

[17] Picker institute and Hervard medical school (2015). The eight principle of patient centered care; overview healthcare.com at www.oneviewhealthcare.com> the eight. Accessed on 26/12/17

[18] Robinson, J., Callister, L., Berry, J., Deaving, K. (2008). Patient centered care and adherence: definitions and application to improve outcomes. Journal of AM Acad nurse pract 20 (12) 29-34

[19] Umar, I., Oche, M.O. and Umar, A.S. (2011). Patient Waiting Time in a Tertiary Health Institution in Northern Nigeria. Journal of public Health and Epidemiology, 3 (2):78-82

[20] Wafula, R.B. (2016). Factors Associated with Patient Waiting Time at Medical Outpatient Clinic: a Case Study of University of Nairobi Health Service. A Project Dissertation Submitted in Partial Fulfilment of the Requirement for the Award of Masters of Science in Health Systems Management in the School of Public Health, University of Nairobi.

[21] Whyte, E. and Goodcare, S. (2016). Patient expected of emergency hospital admission: a cross sectional questionnaire survey. European journal of emergency medicine 23 (3) p203-207

[22] Zineldin, M. (2011). Measuring, evaluating and improving hospital quality Parameters / dimension an integrated healthcare quality approach; international journal healthcare.www.ncbi.nlm.nih.gov pmid: 22204269/indexed for Medlined 